\title{
Hand-arm vibration syndrome: a new clinical classification and an updated British standard guide for hand transmitted vibration
}

Raynaud's phenomenon of occupational origin known in the 1950s as "the vibration syndrome" or "vibration induced white finger (VWF)" has, in the 1980 s, been renamed "the hand-arm vibration syndrome." This occupational hazard has, since 1890, afflicted operators using hand held pneumatic tools (chipping and grinding), chain saws and strimmers, jackleg drills, and electrically driven rotating tools. The government has considered this vibration syndrome as an occupational hazard since 1950, ' finally accepting the condition as a prescribed disease (No A11) in $1985 .{ }^{2}$ The 35 year delay was due to the trivial nature of the injury in most cases, the difficulty of distinguishing occupational from non-occupational causes (primary Raynaud's disease), and the absence of the basic pathophysiological processes underlying cold induced white finger attacks.

After prescription the greatest challenge to examining physicians and vascular surgeons lies in the assessment, classification, and prognosis in vibration induced cases. Since 1967 the Taylor-Pelmear stage classification $^{3}$ has been used internationally with the emphasis on the deficient and sensitive digital circulation by recording the number, extent and duration of white finger attacks. In the early (stage 1) phase there is no evidence of reduced work performance, loss of employment, or interference with social, home, or hobby activities. The degree of blanching is minor, being confined to the finger tips. In advanced cases (stage 3 ) there is blanching of digits to the finger roots, with loss of fine touch and manual dexterity with restrictions at work, in the home, and cessation of hobbies where reduced environmental temperatures provoke numerous attacks daily. With continued exposure to vibration ulceration and tissue necrosis of the finger tips indicate occlusion of the digital arteries. ${ }^{4}$ This early classification requires updating since, over the years, deficiencies have arisen; the assessment is largely dependent on the subjects' own history of attacks, an in-built seasonal component-attacks more frequent in the winter-raised difficulties in hot and cold climates, quantifying disablement and impairment such as "clumsiness" and "loss of dexterity" were impossible without objective tests, and distinguishing intermediate injury (stage 2) with different examiners gave varying results. Clinical examinations were further complicated by the absence of specific and precise objective tests defining the deficiencies in the arterial, sensory, and musculoskeletal systems. It was possible, however, to carry out field surveys of vibration exposed populations by occupational history questionnaires, interviews, attempting to define impairment, and a general medical examination. The latter was found to be essential for medicolegal purposes to exclude primary Raynaud's disease, digital fractures and lacerations, large vessel obstruction (costoclavicular syndrome), polyneuropathies, and collagen and rheumatic disease. Recently the carpal tunnel syndrome ${ }^{5}$ has been recognised as being present in varying proportions in hand-arm vibration injuries.

After international hand-arm conferences in 1972 (Dundee), 1975 (Cincinnati), 1981 (Ottawa), and 1985 (Stockholm) a workshop was set up in 1986 in Stockholm to revise the Taylor-Pelmear classification. A "two-tier" Stockholm classification ${ }^{67}$ removed the difficulties associated with social and personal disabilities, reduced the importance of a subjective history, and abolished the seasonal aspects of the syndrome. The first tier retains the dominant symptomatology found in cold induced Raynaud's phenomenon (stages 1 to 4 ) without the parallel disability and impairment scale but with the addition of a score indicating the number of affected blanched fingers determined separately for each hand. The second tier recognises the importance of the pathological damage known to occur to the mechanoreceptors, the thermoreceptors, and the nocioreceptors of the skin through the sensoneural afferent fibres. The first symptomatic stage (ISN) consists of episodic finger 
numbness with or without tingling. The second ( $2 \mathrm{SN})$ involves, in addition to ISN, reduced sensory perception. The third, in addition to the symptoms of ISN and $2 \mathrm{SN}$, has reduced tactile discrimination and manipulative dexterity.

In both scales objective tests will be required and thus now assume a new dimension. In the vascular scale cold provocation tests are recommended. ${ }^{8-10}$ In the neurological scale tactile function (two point and depth sense aesthesiometry ${ }^{11-13}$ ) and vibrotactile threshold measurements ${ }^{14}$ are required. These tests are conducted on each finger and thumb of both hands. It is also proposed that the sensory tests traditionally used by neurologists (fine touch, pain, and temperature) be added to increase the accuracy of the final SN staging. ${ }^{15}$

From the international conferences evidence has grown that the vascular and neurological components develop independently, ${ }^{16}$ thus supporting the separation inherent in the Stockholm revision. Recognition of the neurological component will require more vigilance by physicians in the differential diagnosis of vibration exposed subjects to exclude polyneuropathies. ${ }^{17}$ Measurement of nerve conduction velocities may also become routine, especially in view of the carpal tunnel involvement thought to be present to some degree in manipulating heavy hand held vibratory tools but not necessarily due to vibration.

Whereas progress has been made in the pathophysiology and in the clinical assessment, it is disappointing to find that the design of hand held vibratory tools, in particular chipping hammers and road drills, has made little progress over the past 60 years. One reason is that no statutory guide lines for vibration limits have been laid down on which tool manufacturers could base new antivibration designs. An important advance has now been made with the publication of BS $6842: 1987^{18}$ replacing DD43:1975, which gives details of methodology, measuring techniques, and "guide" vibration limits for hand transmitted vibration. This guide contains preventive measures including regular tool maintenance and recommendation for routine medical surveillance of vibration exposed populations. The new British Standard Guide, together with the Stockholm classification, will enable research workers internationally to obtain reliable dose/response data for the vibration syndrome and will, we hope, reduce an occupational hazard first reported in $1911^{19}$ but still one of our major workshop hazards.

W TAYLOR

\section{References}

1 Department of Health and Social Security. Reports of Industrial Injuries Advisory Council ( Social Security Act 1975) on vibration white finger. London: HMSO 1954, 1970, 1975, 1981.

2 Department of Health and Social Security. Industrial injuries, prescribed diseases. Amendment regulations 1985. London: HMSO 1985. (SI No 1985/159.)

3 Taylor W, Brammer AJ. Introduction to proceedings of $3 \mathrm{rd}$ international conference on hand-arm vibration. In: Brammer $\mathrm{AJ}$, Taylor $\mathrm{W}$, eds. Vibration effects on the hand and arm in industry. New York: Wiley, 1982:1-12.

4 Taylor W, Ogston S, Brammer AJ. A clinical assessment of seventy-eight cases of the hand-arm vibration syndrome. Scand $J$ Work Environ Health 1986;12:265-8.

5 Lukas E. Peripheral nervous system and hand-arm vibration exposure. In: Brammer AJ, Taylor W, eds. Vibration effects on the hand and arm in industry. New York: Wiley, 1981:39-43.

6 Gemme G, Pyykkö I, Taylor W, Pelmear PL. The Stockholm workshop scale for the classification of cold-induced Raynaud's phenomenon in the hand-arm vibration syndrome (revision of the Taylor-Pelmear scale). Scand J Work Environ Health 1987;13:275-8.

7 Brammer AJ, Taylor W, Lundborg G. Sensorineural stages of the hand-arm vibration syndrome. Scand $J$ Work Environ Health 1987;13:279-83.

8 Juul C, Nielsen SL. Locally induced digital vasospasm detected by delayed rewarming in Raynaud's phenomenon of occupational origin. Br J Ind Med 1981;38:87-90.

9 Welsh CL. Digital rewarming time in the assessment of vibrationinduced white finger. Scand $J$ Work Environ Health 1986;12:249-50.

10 Pyykkö I, Färkkilä M, Korhonen O, Starck J, Jäntti V. Cold provocation tests in the evaluation of vibration-induced white finger. Scand J Work Environ Health 1986;12:254-8.

11 Carlson WS, Samueloff S, Taylor W, Wasserman DE. Instrumentation for measurement of sensory loss in the fingertips. J Occup Med 1979;21:260-4.

12 Chatterjee DS. A new depth-sense esthesiometer. A comparative study on sensitivity. Scand J Work Environ Health 1987;13:3235 .

13 Harada N. Esthiometry, nail compression and other functional tests used in Japan for evaluating the hand-arm vibration syndrome. Scand J Work Environ Health 1987;13:330-3.

14 Hayward RA, Griffin MJ. Measures of vibrotactile sensitivity in persons exposed to hand-arm vibration. Scand J Work Environ Health 1986;12:423-7.

15 Harada N, Matsumoto T. Validity of various function tests performed in Japan as a screening test for vibration syndrome. Int Arch Occup Environ Health 1984;54:283-93.

16 Brammer AJ, Piercy JE, Auger PL. Assessment of impaired tactile sensation: a pilot study. Scand J Work Environ Health 1987;13:380-4

17 Juntunen J, Matikainen E, Seppäläinen AM, Laine A. Peripheral neuropathy and vibration syndrome. Int Arch Occup Environ Health 1983;52:17-24.

18 British Standard Guide to measurement and evaluation of human exposure to vibration transmitted to the hand. London: British Standards Institution, 1987. (BS 6842.)

19 Loriga G. Il lavoro con i martelli pneumatici. Boll Inspett Lavoro (cited by TEL Ekyl). Occupation and health supplement. Geneva: International Labour Office, 1938.

Department of Community Medicine,

University of Dundee,

Ninewells Medical School,

Dundee DDI 9SY, UK. 